\title{
Use of viscoelastic substance in ophthalmic surgery - focus on sodium hyaluronate
}

\section{Tomomi Higashide \\ Kazuhisa Sugiyama}

Department of Ophthalmology, Kanazawa University Graduate School of Medical Science, Kanazawa, Japan
Correspondence:Tomomi Higashide Department of Ophthalmology, Kanazawa University Graduate School of Medical Science, I3-I Takara-machi, Kanazawa, Ishikawa 920864I, Japan

Tel +8I 762652403

Fax 81 762229660

Email eyetomo@kenroku.kanazawa-u.ac.jp

\begin{abstract}
Among viscoelastic substances, sodium hyaluronate has become the most popular for intraocular surgeries since the introduction of Healon ${ }^{\circledR}$ (sodium hyaluronate $1 \%, 4 \times 10^{6}$ daltons) in 1979. This review focuses on the recent development of a new generation of sodium hyaluronate agents with new rheologic properties and the relevant new techniques used in cataract, glaucoma, corneal, and vitreoretinal surgeries. The introduction of sodium hyaluronate agents with different rheologic properties has improved the safety and reliability of intraocular surgeries. Although there have been numerous studies reporting the effectiveness of viscoelastic substances in intraocular surgeries, rigorous validation by multi-center randomized control trials is lacking in many cases. At present, no single viscoelastic agent is most suitable to all of the various intraocular surgical techniques. Therefore, ophthalmologic surgeons should keep up with recent developments of viscoelastic agents and relevant surgical techniques for better patient care.
\end{abstract}

Keywords: sodium hyaluronate, cataract surgery, glaucoma surgery, corneal transplantation, vitreoretinal surgery

Sodium hyaluronate (hyaluronic acid or hyaluronan) is a naturally occurring, highmolecular-mass, polysaccharide present in the extracellular matrix of connective tissues. It is also found in the aqueous humor and the vitreous and coats the corneal endothelium (Balazs 1983). Sodium hyaluronate, and other viscoelastic substances including methylcellulose, chondroitin sulfate, polyacrylamide, and collagen, have been used in intraocular surgery since the 1970s (Liesegang 1990).

Since the introduction of Healon ${ }^{\circledR}$ (sodium hyaluronate $1 \%, 4 \times 10^{6}$ daltons) in 1979 (Balazs et al 1979), sodium hyaluronate has become the most popular and indispensable viscoelastic substance for use in intraocular surgery. Comprehensive reviews published since then have described pharmacological, physiological, and clinical aspects of sodium hyaluronate in ophthalmologic applications in detail (Liesegang 1990; Goa and Benfield 1994). Along with the advent of a new generation of sodium hyaluronates, these compounds rapidly became essential tools for integral parts of intraocular surgery; and the term ophthalmic viscosurgical devices (OVDs) for viscoelastic substances was introduced in the beginning of this century. This review focuses on recent developments in the application of sodium hyaluronates to various intraocular surgeries.

\section{Sodium hyaluronate in the early I990s}

In the early 1990s, sodium hyaluronate agents could be classified as cohesive (eg, Healon ${ }^{\circledR}$; HealonGV ${ }^{\circledR}$, sodium hyaluronate $1.4 \%, 5 \times 10^{6}$ daltons) or dispersive (eg, Viscoat ${ }^{\circledR}$, sodium hyaluronate $3 \%, 5 \times 10^{5}$ daltons - chondroitin sulfate $4 \%$ ). Cohesiveness, which means the degree to which a material adheres to itself, is a function of molecular weight and elasticity and is proportional to the viscosity (a measure of its resistance to flow) at zero shear rate (Liesegang 1990). The viscosity is a function of the molecular weight, concentration, and temperature. The plot of dynamic viscosity 
against shear rate (lower viscosity at higher shear rate) reveals the pseudoplasticity of sodium hyaluronate. High pseudoplasticity facilitates injection of sodium hyaluronate through a small-gauge cannula. Elasticity is the tendency of a material to return to its original shape after being stretched or compressed. Long-chain molecules tend to be more elastic than short-chain molecules.

Cohesive agents have long molecular chains (high molecular weight) and are strongly entangled, whereas dispersive agents have low molecular weight and short molecular chains. Maintenance of anterior chamber depth and easy removal by aspiration are desirable consequences of cohesiveness, whereas coating the corneal endothelium is best done with dispersive materials.

\section{New generation of sodium hyaluronate agents Healon ${ }^{\circledR 5}$}

In 1998, a new sodium hyaluronate agent, Healon ${ }^{\circledR} 5$ (sodium hyaluronate $2.3 \%, 4 \times 10^{6}$ daltons), was introduced. Because of its higher concentration, Healon ${ }^{\circledR} 5$ has even higher viscosity at rest $\left(7 \times 10^{6} \mathrm{mPa} / \mathrm{s}\right)$ than superviscous cohesive HealonGV ${ }^{\circledR}\left(2 \times 10^{6} \mathrm{mPas}\right)$. Healon ${ }^{\circledR} 5$ behaves like the superviscous cohesives at low shear rate, but its distinguishing property, which is solid-like behavior due to its rigid molecular structure, appears at high shear rate. The biphasic behavior of Healon ${ }^{\circledR} 5$ created a new class of OVDs termed viscoadaptive (Arshinoff 1999A). Healon ${ }^{\circledR} 5$ is also called pseudodispersive because fracturing that occurs due to its high rigidity before being sucked into the irrigation/aspiration port makes its complete removal more difficult than removal of cohesive OVDs. In contrast, dispersive OVDs such as Viscoat ${ }^{\circledR}$ are resistant to aspiration because lack of sufficient cohesion allows only small pieces to be aspirated at a time (Arshinoff and Wong 2003). A randomized prospective study showed that Healon ${ }^{\circledR} 5$ caused an intraocular pressure (IOP) increase 4 hours postoperatively that was not significantly different from that caused by OcuCoat ${ }^{\circledR}$ and Celoftal ${ }^{\circledR}$ (hydroxypropyl methylcellulose $2.0 \%$ ), Viscoat ${ }^{\circledR}$, and Healon $\mathrm{GV}^{\circledR}$, and it also resulted in the lowest mean corneal endothelial cell loss (Holzer 2001). In another randomized multicenter clinical trial comparing Healon ${ }^{\circledR} 5$ and Healon ${ }^{\circledR}$, Healon ${ }^{\circledR} 5$ was rated better than Healon ${ }^{\circledR}$ in retention during phacoemulsification, in anterior chamber maintenance during continuous curvilinear capsulorhexis (CCC), and in facilitation of intraocular lens (IOL) implantation, whereas it was more difficult to inject and remove than Healon ${ }^{\circledR}$ (Oshika et al 2004). Furthermore, studies using animal eyes found that Healon ${ }^{\circledR} 5$ was more resistant to removal than DisCoVisc ${ }^{\circledR}$, a new class of OVD as described below (Bissen-Miyajima 2006; Oshika et al 2006).

To overcome the problem of Healon ${ }^{\circledR} 5$ removal, two removal techniques are commonly used. One is the rock'n roll technique in which the irrigation/aspiration handpiece is moved in a circular fashion in the anterior chamber at the iris plane using gentle pressure with the handpiece on the edge of the IOL optic (Arshinoff 1997). The other is a two-compartment (behind-the-lens) technique in which the irrigation/aspiration tip is first placed behind the IOL optic to remove the OVD in the capsular bag while the anterior chamber is still filled with the OVD, and then it is moved into the anterior chamber to remove the remaining OVD there (Tetz and Holzer 2000). In a prospective randomized study of 159 patients comparing the two removal techniques, the two-compartment technique had a significantly shorter mean Healon ${ }^{\circledR} 5$-removal time and a lower mean IOP 5 hours after surgery than did the rock'n roll technique, suggesting that the two-compartment technique is more effective than the rock'n roll technique (Zetterström et al 2002).

However, for surgeons who do not like to place the irrigation/aspiration tip behind the IOL, Cionni et al (2004) described the empty-bag technique for injecting an acrylic foldable IOL through an injector using Healon ${ }^{\circledR} 5$. In this technique, Healon ${ }^{\circledR} 5$ is placed in the anterior chamber and then the capsular bag is expanded with balanced salt solution before IOL implantation. The authors concluded that the technique can often eliminate the need to place the irrigation/aspiration tip behind the IOL optic to remove Healon ${ }^{\circledR} 5$ completely. A similar technique was also reported by Arshinoff (2002) as an application of the ultimate softshell technique described below.

IOL material is reported to have a significant effect on the removal time of Healon ${ }^{\circledR} 5$ (Auffarth et al 2004A). The hydrophobic acrylic IOL allows adhesion of Healon ${ }^{\circledR} 5$ more than PMMA or silicone IOLs and, therefore, has the longest removal time.

\section{DisCoVisc ${ }^{\circledR}$}

The quest for more ideal OVDs for cataract surgery yielded DisCoVisc ${ }^{\circledR}$ (sodium hyaluronate 1.6\%,1.7 $\times 10^{6}$ daltons - chondroitin sulfate 4\%), which belongs to another new class of OVD called viscous dispersives, in 2003. DisCoVisc $^{\circledR}$ possesses a zero-shear viscosity similar to Healon $^{\circledR}$, but is dispersive like Viscoat ${ }^{\circledR}$ (Arshinoff and Jafari 2005). DisCoVisc ${ }^{\circledR}$ belongs to the viscous cohesives according 
to the OVD classification due to its zero-shear viscosity, but its dispersive property does not fit this classification. Earlier OVDs had a cohesion property that correlated highly with zero-shear viscosity. The dissociation of viscosity and cohesion in DisCoVisc ${ }^{\circledR}$ was discovered by measurement of OVD cohesion with the Poyer assay method (Poyer et al 1998). A new OVD classification was defined using zero-shear viscosity and cohesion independently (Arshinoff and Jafari 2005).

The dispersive property of DisCoVisc ${ }^{\circledR}$ was confirmed in several studies. OVD retention was measured between the corneal endothelium and the anterior chamber using in vivo confocal microscopy after simulated phacoemulsification in rabbit eyes (Petroll et al 2005). The authors found that OVD retention of DisCoVisc ${ }^{\circledR}$ was comparable to Viscoat ${ }^{\circledR}$ and was significantly greater than that of Provisc ${ }^{\circledR}$ (sodium hyaluronate $1 \%, 1.9 \times 10^{6}$ daltons), Healon ${ }^{\circledR}$, Healon $^{\circledR} 5$, and Amvisc Plus ${ }^{\circledR}$ (sodium hyaluronate $1.6 \%, 1.5 \times 10^{6}$ daltons). The results suggest that DisCoVisc ${ }^{\circledR}$ may provide good corneal endothelial cell protection during phacoemulsification that is comparable to Viscoat $^{\circledR}$. Bissen-Miyajima (2006) recorded the behavior of OVDs stained with fluorescein during phacoemulsification and IOL implantation surgery performed in porcine eyes, and found that DisCoVisc ${ }^{\circledR}$, Viscoat ${ }^{\circledR}$, and Healon ${ }^{\circledR} 5$ were not aspirated during phacoemulsification and that removal time with the irrigation/aspiration tip was significantly shorter with DisCoVisc $^{\circledR}$ than with Viscoat ${ }^{\circledR}$ or Healon ${ }^{\circledR} 5$. Furthermore, using a similar experimental model, Oshika et al (2006) reported that DisCoVisc ${ }^{\circledR}$ was retained better in the anterior chamber and was easier to remove in comparison with Healon ${ }^{\circledR} 5$ and concluded that DisCoVisc ${ }^{\circledR}$ is highly advantageous when performing cataract surgery with a single OVD.

\section{VisThesia ${ }^{\circledR}$}

VisThesia $^{\circledR}$ is composed of 2 products: VisThesia Topical (sodium hyaluronate $0.3 \%$, lidocaine $2 \%$ ), for corneal hydration and topical anesthesia, and VisThesia Intracameral (sodium hyaluronate $1.5 \%$ and lidocaine 1\%), for highviscosity, cohesive OVD and intracameral anesthesia. Randomized trials found that intracameral lidocaine $1 \%$ used as a supplement to topical anesthesia may slightly reduce patients discomfort and may not be toxic to the corneal endothelial cells when applied once prior to capsulorhexis (Carino et al 1998; Garcia et al 1998; Tseng and Chen 1998; Gillow et al 1999). As for VisThesia ${ }^{\circledR}$, Poyales-Galan and Pirazzoli (2005) reported corneal endothelial cell loss comparable to that reported for similar OVDs, whereas Perone et al (2007) reported worse corneal endothelial protection than with DuoVisc ${ }^{\circledR}\left(\right.$ VIscoat $^{\circledR}$ plus ProVisc ${ }^{\circledR}$ ) suggesting lidocaine $1 \%$ may be toxic when used as an ingredient of OVDs. Removal properties of VisThesia ${ }^{\circledR}$ should be similar to those of sodium hyaluronate $1.5 \%$ because a mixture of lidocaine $1.0 \%$ with sodium hyaluronate $1.5 \%$ does not significantly alter its removal time from the capsular bag of postmortem human eyes (Pandey 2003).

\section{Cataract surgery}

The main purpose for using sodium hyaluronate in cataract surgery is to maintain a stable anterior chamber depth and protect the corneal endothelial cells from being damaged during the entire surgical procedure. The advent of sodium hyaluronate with different rheologic properties has promoted the development of techniques in cataract surgery that decrease surgical complications and make challenging cases easier. However, postoperative elevation of IOP as an adverse effect of using sodium hyaluronate still remains a matter of concern for most surgeons.

\section{Soft-shell technique}

The technique (Arshinoff 1999B) using dispersive and cohesive OVDs creates a smooth, flat layer of dispersive OVD (Viscoat ${ }^{\circledR}$ ) adjacent to the corneal endothelium over a high-viscosity, cohesive OVD such as Healon ${ }^{\circledR}$. This technique is effective in reducing corneal endothelial cell loss after phacoemulsification surgery, especially in eyes with dense nuclear opacity, when compared with results using a single cohesive or dispersive OVD only (Miyata et al 2002; Kim and Joo 2004). A Medline search did not find any articles that compared the soft shell technique with DiscoVisc $^{\circledast}$, a new viscous dispersive OVD. However, according to in vitro studies (Bissen-Miyajima 2006; Oshika et al 2006), removal will be better with DiscoVisc ${ }^{\circledR}$ than with the soft shell technique because DiscoVisc ${ }^{\circledR}$ requires a shorter aspiration time by an irrigation/aspiration tip than Viscoat $^{\circledR}$. As for endothelial cell protection by DiscoVisc ${ }^{\circledR}$, it may be similar to that of the soft shell technique because residual OVD thickness of DiscoVisc ${ }^{\circledR}$ following simulated phacoemulsification was similar to that of Viscoat ${ }^{\circledR}$ (Petroll et al 2005). Clinical studies are needed to determine whether a single OVD, DiscoVisc ${ }^{\circledR}$, can replace the soft shell technique which requires two OVDs.

Arshinoff (2002) has developed a new technique called the ultimate soft-shell technique. This technique compartmentalizes the anterior chamber using the ultimate low-viscosity fluid (balanced salt solution or trypan blue) underneath viscoadaptive OVDs (Healon5 ${ }^{\circledR}$ or I-Visc Phaco ${ }^{\circledR}$, sodium hyaluronate $2.5 \%$ ) with which the anterior chamber is filled to the desired extent (for capsulorhexis, $60 \%-80 \%$; for capsular staining, $90 \%$; for 
IOL implantation, 60\%). The technique reduces the resistance to advancing the capsulorhexis with a needle or forceps while maintaining tamponade to the lens surface well, and also reduces the amount of dye required for capsular staining of mature or white cataracts. Furthermore, this technique can be applied to the IOL implantation followed by an easy aspiration of OVDs in a way similar to the empty-bag technique described by Cionni et al (2004).

\section{Intraoperative floppy iris syndrome (IFIS)}

Chang and Campbell (2005) reported a new small-pupil syndrome associated with tamsulosin, a systemic $\alpha-1$ blocker used to treat benign prostatic hypertrophy. The clinical intraoperative triad of the syndrome consists of fluttering and billowing of the iris stroma caused by ordinary intraocular fluid currents, a propensity for iris prolapse through the phacoemulsification and/or side-port incisions, and progressive constriction of the pupil during surgery. In a prospective study of 900 consecutive cataract surgeries, they found the prevalence of IFIS to be $2.2 \%$, and $94 \%$ of the IFIS cases had a history of taking systemic tamsulosin. In order to complete cataract surgery safely in eyes with IFIS syndrome, Healon ${ }^{\circledR} 5$ may help to mechanically expand the pupil (viscomydriasis) and prevent the iris from prolapsing by adding tone to the iris (Chang and Campbell 2005). Furthermore, Arshinoff (2006) described detailed methods to deal with eyes with IFIS syndrome that involve injecting Viscoat ${ }^{\circledR}$, Healon ${ }^{\circledR} 5$, and balanced salt solution consecutively into the anterior chamber (modified soft-shell technique - ultimate soft-shell technique).

\section{Capsulorhexis in pediatric cataract surgery}

Since the introduction by Gimbell and Neuhann (1990), CCC has become a standard technique in cataract surgery. However, there are challenging cases in which it is difficult to complete CCC. Among them, pediatric cataract is one of the most difficult categories because the pediatric lens capsule is more elastic than the adult lens capsule and the posterior pressure which pushs up the lens is higher in pediatric eyes than in adult eyes. By using Healon ${ }^{\circledR}$, Jeng et al (2004) successfully performed CCC in 9 of 10 eyes ( $6.4 \pm 1.4$ years), but they completed only 7 of 15 eyes with Healon $^{\circledR}$ or Viscoat ${ }^{\circledR}(7.6 \pm 1.4$ years $)$. Furthermore, even in much younger cases (median age of surgery $=9$ months; range, 1-54 months), Gibbon and Quinn (2006) reported that CCC was successfully completed with Healon ${ }^{\circledR} 5$ in 21 of 22 eyes. They tried and failed CCC with Healon $\mathrm{GV}^{\circledR}$ in 2 eyes, and postulated that the super-viscous cohesive property of
Healon $^{\circledR} 5$ made CCC completion possible in pediatric eyes by stabilizing the anterior chamber depth better.

\section{Use of sodium hyaluronate in cases of posterior capsule rupture}

Sodium hyaluronate is sometimes helpful to tamponade a posterior capsule rupture for subsequent IOL implantation. However, Shihota et al (2003) reported 4 cases with intractable glaucoma after complicated phacoemulsificaiton during which Healon ${ }^{\circledR}$ was used to tamponade a central posterior capsule rupture. Incomplete removal of Healon ${ }^{\circledR}$ in the vitreous cavity was considered to be a primary reason for severe IOP elevation, and the authors recommended early removal of OVDs by pars plana vitrectomy in the presence of ultrasonographic evidence of intravitreal OVDs.

Chang and Packard (2003) reported the usefulness of Viscoat $^{\circledR}$ for retrieval of a partially descended nucleus after posterior capsule rupture. They injected Viscoat ${ }^{\circledR}$ through a pars plana incision to elevate the nuclear pieces into the anterior chamber. They selected Viscoat ${ }^{\circledR}$ for this technique because its dispersive property makes it less likely to cause a protracted IOP rise in case of incomplete removal and it may block further vitreous prolapse more effectively than other high-molecular weight cohesive OVDs. Actually, they experienced no early postoperative IOP elevation in 8 consecutive patients.

\section{Anterior lens capsule staining with dyes}

Indocyanine green (Horiguchi et al 1998) and trypan blue (Melles et al 1999B) are widely used for better visualization of the anterior lens capsule during CCC in difficult cases such as white or brunescent cataracts. In order to prevent dyes from staining other intraocular structures excessively, OVDs are used concomitantly, but controlling the staining area is sometimes difficult. In this regard, Arshinoff (2002) reported the usefulness of the ultimate soft-shell technique for capsular staining as described above. Marques et al (2004) reported a similar 3-step technique that prevents uncontrolled dispersion and excessive accumulation of dye within an OVD. They injected Healon ${ }^{\circledR} 5$ to fill the anterior chamber, then injected balanced salt solution gently onto the anterior lens capsule, and finally injected the dye slowly through a specially-designed 27 -gauge cannula.

\section{Postoperative complications and OVDs IOP elevation by OVDs}

A number of studies have shown that all viscoelastic substances are capable of increasing IOP in the early postoperative period (Liesegang 1990; Goa and Benfield 1994). The IOP 
elevation by viscoelastic substances is caused by a reduction of aqueous outflow due to blockage of the trabecular meshwork where the fluids exit the eye. Therefore, complete removal of OVDs is recommended after IOL implantation. The IOP elevation is usually transient, peaking at 4 to 7 hours postoperatively and returning to baseline within several days, but the maximum IOP may exceed $30 \mathrm{mmHg}$. Therefore, careful monitoring of IOP and IOP-lowering therapy may be necessary, especially in patients with glaucoma who have a compromised outflow facility. Molecular characteristic of OVDs should have significant effects on the likelihood of IOP elevation. Torngren et al (2000) found positive correlations between concentration and maximum IOP increase and between molecular weight and time to peak in rabbit eyes after aqueous exchange with OVDs. However, no consensus has been reached among clinical studies as to which OVD causes most or least elevation of IOP postoperatively in cataract surgery. The lack of consensus is due partly to the variability of patient characteristics (Arshinoff et al 2002), the amount of OVDs remaining in the eye at the end of surgery, and the timing of IOP measurements (Rainer et al 2005). For example, Viscoat ${ }^{\circledR}$, an OVD with low-molecular weight and short chain, is supposed to pass through the trabecular meshwork easily and be less likely to cause IOP elevation, whereas it is most resistant to complete removal due to its dispersive property. Rainer et al (2005) reported significant IOP increases during the first 24 hours, peaking at 1 hour after surgery $(13.4 \pm 9.4 \mathrm{~mm} \mathrm{Hg})$, in eyes that were operated with Viscoat ${ }^{\circledR}$. As for Healon $5^{\circledR}$, randomized studies found that the postoperative IOP in Healon $5^{\circledR}$-treated eyes was less than that in Viscoat ${ }^{\circledR}$-treated eyes at 6 hours, but was not significantly different from Viscoat ${ }^{\circledR}$-treated eyes at 1 day (Rainer et al 2000). Other studies found no difference in early postoperative IOP between Healon $5^{\circledR}$-treated and other OVD-treated eyes $\left(\mathrm{OcuCoat}^{\circledR}, \mathrm{Celoftal}^{\circledR}\right.$, Viscoat ${ }^{\circledR}$ and Healon $\mathrm{GV}^{\circledR}$, Holzer et al 2001; Healon $\mathrm{GV}^{\circledR}$, Arshinoff et al 2002; Healon ${ }^{\circledR}$, Oshika et al 2004; Amvisc Plus ${ }^{\circledR}$, Moser et al 2004). No randomized studies examining the postoperative IOP increase in DisCoVisc ${ }^{\circledR}$ - or Visthesia ${ }^{\circledR}$-treated eyes have been reported.

A fluorescently-labeled OVD enabled better visualization, facilitated complete removal, and caused a significantly smaller IOP increase than a clear OVD (Smith and Burt 1992). Although this technique has not become a routine procedure yet, it has been used in experimental studies with ex vivo eyes to examine retention or removal of OVDs during cataract surgery (Auffarth et al 2004A; Auffarth et al 2004B; Bissen-Miyajima 2006; Oshika et al 2006).

\section{Mechanism of corneal endothelial cell loss during cataract surgery and the protection by OVDs}

During cataract surgery, mechanical damage from surgical instruments or lens fragments may cause corneal endothelial cell loss, and OVDs have been used for protection since the era of extracapsular cataract extraction began. In addition, ultrasound phacoemulsification causes formation of highly reactive free radicals that are generated by the heat from cavity-implosion of decomposed water (Shimmura et al 1992; Holst et al 1993). The free radicals induce oxidative tissue damage including corneal endothelial cell loss. In this regard, OVDs could reduce the amount of free radicals produced by phacoemulsification in experimental studies (Shimmura et al 1992; Holst et al 1993; Takahashi et al 2002; Camillieri et al 2004; Takahashi et al 2006) and also in a clinical study (Augustin and Dick 2004). Takahashi et al (2006) showed that an OVD's inhibitory effect against free radical formation in the phacoemulsification simulations with an eye model was compatible with its retention properties in the anterior chamber under different irrigation/aspiration settings, and that Viscoat ${ }^{\circledR}$, with a high irrigation/aspiration setting, was superior to Healon ${ }^{\circledR}$, Opegan ${ }^{\circledR}$ (sodium hyaluronate $1 \%$, $0.6-1.2 \times 10^{6}$ daltons) and Healon ${ }^{\circledR} 5$ in suppression of free radical formation.

The heat generation by phacoemulsification, which contributes not only to the corneal endothelial cell loss but also to wound burn and breakdown of the bloodaqueous barrier, was considered by Jurowski et al (2006) by measuring the increase in corneal surface temperature of rabbit eyes during phacoemulsification. They suggested that dispersive OVDs may be more effective in preventing thermal injury.

\section{Glaucoma surgery}

To improve surgical outcome and reduce intraoperative and postoperative complications, sodium hyaluronate has been used for glaucoma surgeries including trabeculectomy and goniotomy. Furthermore, Stegmann et al (1999) established a new non-penetrating glaucoma surgery, viscocanalostomy, using Healon $\mathrm{GV}^{\circledR}$.

\section{Trabeculectomy - intraoperative use of sodium hyaluronate}

Prior to the era of routine use of the antimetabolites mitomycin C (Kitazawa et al 1991) and 5-fluorouracil (Heuer et al 1984), excess filtration immediately after 
trabeculectomy was considered to be necessary for long-term surgical success, especially in difficult cases, but was likely to cause complications such as a flat anterior chamber and hypotony. To solve this problem, a number of studies evaluated the effectiveness of viscous and non-inflammatory sodium hyaluronate in reducing early postoperative complications. In studies with a prospective and randomized design, intracameral or subconjunctival injection of sodium hyaluronate resulted in less frequent hypotony or flattening of the anterior chamber (Alpar 1986; Charteris et al 1991; Barak et al 1992; Gulkilik et al 2006), although negative results were also reported (Hung 1985; Teekhasaenee and Ritch 1986; Raitta et al 1994; Lopes et al 2006).

The inconsistency of the results may stem from the variability of surgical techniques, especially the site and the time that the sodium hyaluronate remained in the eye. As pointed out by Fiore et al (1989), a postoperative shallow anterior chamber may cause corneal endothelial cell loss. The intracameral injection of sodium hyaluronate prior to trabeculectomy, which was randomly assigned, significantly reduced corneal endothelial cell loss without the use of antimetabolites and intraoperative aspiration of sodium hyaluronate (Barak et al 1992) or with adjunctive mitomycin $\mathrm{C}$ and intraoperative removal of sodium hyaluronate (Shin et al 2003). Wilson and Lloyd (1986) found a lower incidence of postoperative hyphema in eyes treated with intracameral sodium hyaluronate and attributed the effect to possible microvascular clotting and a mechanical force by sodium hyaluronate, whereas Raitta et al (1994) reported opposite results. As for bleb morphology, subconjunctival injection of Healon ${ }^{\circledR} 5$ at the conclusion of trabeculectomy with adjunctive antimetabolites (mostly mitomycin $\mathrm{C}$ ) resulted in more diffuse filtering blebs 1 year postoperatively, although the surgical success rate was not different from control eyes (Lopes et al 2006). Subconjunctival injection of Healon ${ }^{\circledR} 5$ was also effective in treating a small conjunctival break that was created during trabeculectomy with adjunctive mitomycin $\mathrm{C}$ and was technically difficult to close by suturing without compromising filtration (Higashide et al 2005). The site of the leakage was successfully plugged in 3 consecutive cases by Healon ${ }^{\circledR} 5$ without suturing due to its superviscous cohesive properties at low shear rate. No leakage from the mildly elevated bleb was observed on the first postoperative day and the technique was associated with no postoperative complications.

One possible drawback of the intraoperative injection of sodium hyaluronate during trabeculectomy is the early postoperative IOP rise which is especially dangerous to eyes with advanced visual field loss (Liebmann et al 1990; Barak et al 1992). Close monitoring of the postoperative IOP is necessary, even though the removal of sodium hyaluronate from the anterior chamber at the conclusion of the surgery may decrease the risk of an IOP rise (Shin et al 2003).

\section{Trabeculectomy - postoperative use of sodium hyaluronate}

Intracameral injection of sodium hyaluronate is reported to be useful to treat a postoperative shallow or flat anterior chamber (Gerber and Cantor 1990; Juzych et al 1992; Osher et al 1996; Salvo et al 1999). A survey reported in 1999 revealed that $75 \%$ of American Glaucoma Society members used sodium hyaluronate (most commonly Healon ${ }^{\circledR}$ ) for anterior chamber reformation (Salvo et al 1999). However, the effect of sodium hyaluronate sometimes does not last long and repeated injection or alternative methods are then required. In expectation of a more prolonged stay and, therefore, better stabilization of the anterior chamber, Healon ${ }^{\circledR} 5$ was used for reformation of a flat anterior chamber with inconsistent success (Hoffman et al 2002; Geyer et al 2003; Gutierrez-Ortiz and Moreno-Lopez 2003). For cases in which Healon ${ }^{\circledR}$ or Healon ${ }^{\circledR} 5$ was ineffective, combined intracameral injection of sulfur hexafluoride, a long-acting gas, and Healon ${ }^{\circledR}$ successfully stabilized the anterior chamber (Geyer et al 2003). A similar technique using perfluoropropane and an OVD was also reported (Kurtz and Leibovitch 2002). For postoperative hypotony, intracameral injection of Healon ${ }^{\circledR} 5$ raised IOP to an extent insufficient to fully improve the hypotonus conditions (Altangerel et al 2006).

\section{Goniotomy}

The effectiveness of sodium hyaluronate in keeping sufficient depth of the anterior chamber also facilitates goniotomy. Arnoult et al (1988) reported that sodium hyaluronate injected intracamerally during goniotomy prevented accidental loss of the anterior chamber, allowed maximal depth of the anterior chamber, diminished intraocular bleeding, and lowered the risk of injury to ocular tissues. In a retrospective study comparing goniotomy with and without Healon ${ }^{\circledR}$, the authors concluded that the use of sodium hyaluronate may increase the success rate and decrease the complication rate by preventing hyphema and flattening of the anterior chamber (Tamcelik and Ozkiris 2004). Intracameral injection of sodium hyaluronate into the anterior chamber may also facilitate goniosynechialysis, another type of goniosurgery. 


\section{Viscocanalostomy}

In 1999, Stegmann et al (1999) reported a new nonpenetrating glaucoma surgery, viscocanalostomy, using Healon $\mathrm{GV}^{\circledR}$ in order to avoid creating filtering blebs in eyes of black African patients with open-angle glaucoma who had a high risk of bleb infections. The authors hypothesized that the aqueous humor diffuses freely into a subscleral space through a window consisting of the Schlemm's canal endothelium and Descemet's membrane and enters into the Schlemm's canal which was dilated by injecting a superviscous cohesive OVD (Healon $\mathrm{GV}^{\circledR}$ ). The presence of OVD in the Schlemm's canal was supposed to prevent fibrosis at the ostia adjacent to the subscleral space. It is not known whether the extent of the dilatation of Schlemm's canal affects surgical success. In viscocanalostomy experiments with human eyes obtained at autopsy, the more viscous Healon ${ }^{\circledR} 5$ was superior to Healon $\mathrm{GV}^{\circledR}$ in dilating Schlemm's canal $6.0 \mathrm{~mm}$ from the flap (Wild et al 2001). Experimental viscocanalostomy in rhesus monkey resulted in microperforation in the endothelial lining of Schlemm's canal that was attributed to the increase in outflow facility (Tamm et al 2004). The authors indicated that the persistence of endothelial defects in Schlemm's canal 1 to 2 months after surgery may be caused by the inhibitory effects of sodium hyaluronate on thrombocyte aggregation.

In another application of sodium hyaluronate in nonpenetrating glaucoma surgery, SKGEL ${ }^{\circledR}$, a reticulated hyaluronic acid implant, was developed for preserving the space under the scleral flap in non-penetrating deep sclerectomy (Sourdille et al 1999). In a study evaluating the effect of SKGEL ${ }^{\circledR}$ in non-penetrating deep sclerectomy, IOP control was better with $\mathrm{SKGEL}^{\circledR}$ than without it (Detry-Morel 2001). SKGEL ${ }^{\circledR}$ was also applied in viscocanalostomy, but a prospective randomized trial in patients with open angle glaucoma failed to show better surgical outcome with SKGEL ${ }^{\circledR}$ when compared with standard viscocanalostomy (Luke et al 2003).

\section{Corneal transplantation}

Sodium hyaluronate is also indispensable to corneal transplantation surgery in several respects including protection of donor corneal endothelial cells (Frost et al 2006). In a case with corneal perforation, trephination of the host cornea is difficult due to hypotony. Healon ${ }^{\circledR} 5$ injected into the anterior chamber temporarily closed the corneal wound and facilitated the trephination (Rado and Berta 2002). Healon ${ }^{\circledR} 5$ also facilitates deep lamellar keratoplasty in difficult cases such as keratoconus that have a relatively high risk of rupturing Descemet's membrane during surgery (Shimmura et al 2005). In the visco-dissection technique to separate Descemet's membrane from posterior stroma (Melles et al 1999A; Melles et al 2000), Healon ${ }^{\circledR} 5$ enabled precise control of visco-dissection and caused no Descemet's membrane ruptures in 4 cases (Shimmura et al 2005).

\section{Vitreoretinal surgery}

Prior to its widespread use for IOL implantation, sodium hyaluronate was used as a substitute for the vitreous in retinal detachment surgery (Balazs et al 1972). Since then, there have been a number of reports of the usefulness of sodium hyaluronate in vitreoretinal surgery. Although sodium hyaluronate as an intraoperative tamponade in difficult cases (Pruett et al 1979) has mostly been replaced by perfluorocarbon liquids (Chang 1987), viscodissection or viscodelamination using sodium hyaluronate is still an effective surgical technique in vitreoretinal surgery (McLeod and James 1988; Grigorian et al 2003).

Recent application of sodium hyaluronate in vitrectomy is for protection of the retina from chemical or mechanical damages. Staining with indocyanine green facilitates visualization and peeling of the internal limiting membrane in eyes with macular holes (Kadonosono et al 2000) and other vitreomacular interface abnormalities. The original preparation of indocyanine green for internal limiting membrane peeling was a mixture of the dye and a low molecular weight OVD (final concentration, $0.06 \%$; osmolarity, 270 mOsm) (Kadonosono et al 2000). Later, a number of clinical and experimental studies raised the possibility of toxicity of indocyanine green to the retinal pigment epithelium (Engelbrecht et al 2002; Ho et al 2003) and to retinal ganglion cells (Iriyama et al 2004; Yamashita et al 2006), and a reduction of the concentration and duration of dye exposure was recommended. In this regard, sodium hyaluronate $2.3 \%$ placed over the macular hole effectively prevented the subretinal migration of indocyanine green through the hole during vitrectomy for retinal detachment with a myopic macular hole (Cacciatori et al 2004). A similar technique was also reported for prevention of the contact between indocyanine green and the retinal pigment epithelium in a macular hole (Saito and Iida 2006). Regarding mechanical protection of the retina, Hanemoto et al (2004) reported that intravitreously injected Healon ${ }^{\circledR 5}$, which covered the posterior pole, prevented retinal damage during removal of a luxated crystalline lens by intravitreal phacoemulsification. 


\section{Conclusions}

Introduction of sodium hyaluronate agents with different rheologic properties and the new techniques that utilize these agents for cataract, glaucoma, corneal, and vitreoretinal surgeries has enabled us to perform intraocular surgeries more safely and reliably. Among the new generation of OVDs, Healon ${ }^{\circledR}$, a viscoadaptive OVD with the highest ability to stabilize the anterior chamber, not only facilitates $\mathrm{CCC}$ in difficult cataract cases but also is useful in glaucoma and corneal surgeries. Healon ${ }^{\circledR} 5$ provides good corneal endothelial protection but its injection and removal are harder than that of cohesive OVDs. DisCoVisc ${ }^{\circledR}$, a viscous dispersive OVD, may be an ideal OVD to perform cataract surgery with a single OVD because it remains well in the anterior chamber during phacoemulsification and is more easily removed by an irrigation/aspiration tip than Viscoat ${ }^{\circledR}$ or Healon ${ }^{\circledR}$. Although there have been numerous studies reporting the effectiveness of viscoelastic substances in intraocular surgeries, many reports are subjective and based on results with a small number of cases. Accordingly, rigorous validation, ideally by multi-center randomized control trials, should help clarify the true effectiveness of OVDs in different kinds of intraocular surgeries. At present, no single OVD is most useful for all of the various intraocular surgical techniques. Therefore, ophthalmologic surgeons should keep up with recent developments of OVDs and relevant surgical techniques for better patient care.

\section{Note}

The authors of this manuscript have no proprietary or financial interest in it.

\section{References}

Alpar JJ. 1986. Sodium hyaluronate (Healon $\left.{ }^{\circledR}\right)$ in glaucoma filtering procedure. Ophthalmic Surg, 17:724-30.

Altangerel U, Rai S, Fontanarosa J, et al. 2006. Intracamaral 2.3\% sodium hyaluronate to treat postoperative hypotony in patients with glaucoma. Ophthalmic Surg Laser Imaging, 37:106-11.

Arnoult JB, Vila-Coro AA, Mazow ML. 1988. Goniotomy with sodium hyaluronate. J Pediatr Ophthalmol Strabismus, 25:18-22.

Arshinoff SA. 1997. Rock'n roll removal of Healon GV. In Arshinoff SA (ed). Proceedings of the 7th Annual National Ophthalmic Speakers Program. Quebec : Medicopea, p. 29-30.

Arshinoff SA. 1999A. Why Healon5? The meaning of "viscoadaptive". Ophthalmic Pract, 17:332-4.

Arshinoff SA. 1999B. Dispersive-cohesive viscoelastic soft shell technique. $J$ Cataract Refract Surg, 25:167-73.

Arshinoff SA. 2002. Using BSS with viscoadaptives in the ultimate softshell technique. J Cataract Refract Surg, 28:1509-14.

Arshinoff SA. 2006. Modified SST-USST for tamsulosin-associated intraocular floppy-iris syndrome. J Cataract Refract Surg, 32:559-61.

Arshinoff SA, Albiani DA, Taylor-Laporte J. 2002. Intraocular pressure after bilateral cataract surgery using Healon, Healon5, and Healon GV. $J$ Cataract Refract Surg, 28:617-25.
Arshinoff SA, Jafari M. 2005. New classification of ophthalmic viscosurgical devices-2005. J Cataract Refract Surg, 31:2167-71.

Arshinoff SA, Wong E. 2003. Understanding, retaining, and removing dispersive and pseudodispersive ophthalmic viscosurgical devices. $J$ Cataract Refract Surg, 29:2318-23.

Auffarth GU, Holzer MP, Vissesook N, et al. 2004A. Removal time and techniques of a viscoadaptive ophthalmic viscosugical device. $J$ Cataract Refract Surg, 30:879-83.

Auffarth GU, Holzer MP, Vissesook N, et al. 2004B. Removal times for a dispersive and a cohesive ophthalmic viscosurgical device correlated with intraocular lens material. J Cataract Refract Surg, 30:2410-4.

Augustin AJ, Dick HB. 2004. Oxidative tissue damage after phacoemulsification: influence of ophthalmic viscosurgical devices. $J$ Cataract Refract Surg, 30:424-7.

Balazs EA. 1983. Sodium hyaluronate and viscosurgery. In Miller D, Stegmann R (eds). Healon, A guide to its use in ophthalmic surgery. New York: Wiley Medical Publishers, p. 5-28.

Balazs EA, Freeman MI, Klöti R, et al. 1972. Hyaluronic acid and the replacement of vitreous and aqueous humor. Mod Probl Ophthalmol, 10:3-21.

Balazs EA. Inventor; Biotrics, Inc, assignee. 1979. Ultrapure hyaluronic acid and the use thereof. US patent 4141973 . October 17, 1979.

Barak A, Alhalel A, Kotas R, et al. 1992. The prospective effect of early intraoperative injection of viscoelastic material in trabeculectomy. Ophthalmic Surg, 23:206-9.

Bissen-Miyajima H. 2006. In vitro behavior of ophthalmic viscosurgical devices during phacoemulsification. J Cataract Refract Surg, 32:1026-31

Cacciatori M, Azzolini M, Sborgia M, et al. 2004. Sodium hyaluronate $2.3 \%$ prevents contact between indocyanine green and retinal pigment epithelium during vitrectomy for highly myopic macular hole retinal detachment. Retina, 24:160-1.

Camillieri G, Nastasi A, Gulino P, et al. 2004. Effects of hyaluronan on free-radical formation, corneal endothelium damage, and inflammation parameters after phacoemulsification in rabbits. J Ocul Pharmacol Ther, 20:151-7.

Carino NS, Slomovic AR, Chung F, et al. 1998. Topical tetracaine versus topical tetracaine plus intracameral lidocaine for cataract surgery. $J$ Cataract Refract Surg, 24:1602-8.

Chang DF, Campbell JR. 2005. Intraoperative floppy iris syndrome associated with tamsulocin. J Cataract Refract Surg, 31:664-73.

Chang DF, Packard RB. 2003. Posterior assisted levitation for nucleous retrieval using Viscoat after posterior capsule rupture. $J$ Cataract Refract Surg, 29:1860-5.

Chang S. 1987. Low viscosity liquid fluorochemicals in vitreous surgery. Am J Ophthalmol, 103:38-43.

Charteris DG, McConnell JM, Adams AD. 1991. Effects of sodium hyaluronate on trabeculectomy filtration blebs. $J R$ Coll Surg Edinb, $36: 107-8$.

Cionni RJ, Temel M, Marques DMV, et al. 2004. Empty-bag technique for acrylic intraocular lens implantation using Healon5. J Cataract Refract Surg, 30:453-6.

Detry-Morel M. 2001. Non penetrating deep sclerectomy (NPDS) with SKGEL implant and/ or 5-fluorouracil (5-FU). Bull Soc Belge Ophthalmol, 280:23-32.

Engelbrecht NE, Freeman J, Sternberg P Jr, et al. 2002. Retinal pigment epithelial changes after macular hole surgery with indocyanine green-assisted internal limiting membrane peeling. Am J Ophthalmol, 133:89-94.

Fiore PM, Richter CU, Arzeno G, et al. 1989. The effect of anterior chamber depth on endothelial cell count after filtration surgery. Arch Ophthalmol, 107:1609-11.

Frost NA, Wu J, Lai TF, et al. 2006. A review of randomized controlled trials of penetrating keratoplasty techniques. Ophthalmology, 113:942-9.

Garcia A, Loureiro F, Limao A, et al. 1998. Preservative-free lidocaine $1 \%$ anterior chamber irrigation as an adjunct to topical anesthesia. $J$ Cataract Refract Surg, 24:403-6. 
Gerber SL, Cantor LB. 1990. Slit lamp reformation of the anterior chamber following trabeculectomy. Ophthalmic surg, 21:404-6.

Geyer O, Segev E, Steinberg JM, et al. 2003. Stabilization of posttrabeculectomy flat anterior chamber with Healon and sulfur hexafluoride. J cataract Refract Surg, 29:2026-8.

Gibbon CEA, Quinn AG. 2006. Use of capsulorhexis and Healon5 in children younger than 5 years of age. J AAPOS, 10:180-1.

Gimbel HV, Nauhann T. 1990. Development, advantages, and methods of the continuous curvilinear capsulorhexis technique. J Cataract Refract Surg, 16:31-7.

Goa KL, Benfield P. 1994. Hyaluronic acid. A review of its pharmacology and use as a surgical aid in ophthalmology, and its therapeutic potentials in joint disease and wound healing. Drugs, 47:536-66.

Grigorian RA, Castellarin A, Fegan R, et al. 2003. Epiretinal membrane removal in diabetic eyes: comparison of viscodissection with conventional methods of membrane peeling. Br J Ophthalmol, 87:737-41.

Gillow T, Scotcher SM, Deutsch J, et al. 1999. Efficacy of supplementary intracameral lidocaine in routine phacoemulsification under topical anesthesia. Ophthalmology, 106:2173-7.

Gulkilik G, Kocabora S, Engin G, et al. 2006. Sodium hyaluronate in trabeculectomy: effect on early complications. Clin Experiment Ophthalmol, 34:421-4.

Gutierrez-Ortiz C, Moreno-Lopez M. 2003. Healon5 as a treatment option for recurrent flat anterior chamber after trabeculectomy. $J$ cataract Refract Surg, 29:635.

Hanemoto T, Ideta H, Kawasaki T. 2004. Retinal protection using a viscoadaptive viscoelastic agent during removal of a luxated crystalline lens by intravitreal phacoemulsification. Am J Ophthalmol, 137:936-8.

Heuer DK, Parrish RK II, Gressel MG, et al. 1984. 5-fluorouracil and glaucoma filtering surgery II. A pilot study. Ophthalmology, 91:384-94.

Higashide T, Tagawa S, Sugiyama K. 2005. Intraoperative Healon5 injection into blebs for small conjunctival breaks created during trabeculectomy. $J$ Cataract Refract Surg, 31:1279-82.

Ho JD, Tsai RJ, Chen SN, et al. 2003. Cytotoxicity of indocyanine green on retinal pigment epithelium: implications for macular hole surgery. Arch Ophthalmol, 121:1423-9.

Hoffman RS, Fine IH, Packer M. 2002. Stabilization of flat anterior chamber after trabeculectomy with Healon5. J cataract Refract Surg, 28:712-4.

Holst A, Rolfsen W, Svensson B, et al. 1993. Formation of free radicals during phacoemulsification. Curr Eye Res, 12:359-65.

Holzer MP, Tetz MR, Auffarth GU, et al. 2001. Effect of Healon5 and 4 other viscoelastic substances on intraocular pressure and endothelium after cataract surgery. $J$ Cataract Refract Surg, 27:213-8.

Horiguchi M, Miyake K, Ohta I, et al. 1998. Staining of the lens capsule for circular continuous capsulorhexis in eyes with white cataract. Arch Ophthalmol, 116:535-7.

Hung SO. 1985. Role of sodium hyaluronate (Healonid) in triangular flap trabeculectomy. Br J Ophthalmol, 69:46-50.

Iriyama A, Uchida S, Yanagi Y, et al. 2004. Effects of indocyanine green on retinal ganglion cells. Invest Ophthalmol Vis Sci, 45:943-7.

Jeng BH, Hoyt CS, McLeod SD. 2004. Completion rate of continuous curviliear capsulorhexis in pediatric cataract surgery using different viscoelastic materials. J Cataract Refract Surg, 30:85-88.

Jurouski P, Goś R, Kuśmierczyk J, et al. 2006. Quantitative thermographic analysis of viscoelastic substances in an experimental study in rabbits. $J$ Cataract Refract Surg, 32:137-40.

Juzych MS, Parrow KA, Shin DH, et al. 1992. Adjunctive viscoelastic therapy for postoperative ciliary block. Ophthalmic Surg, 23:784-8.

Kadonosono K, Itoh N, Uchio E, et al. 2000. Staining of internal limiting membrane in macular hole surgery. Arch Ophthalmol, 118:1116-8.

Kim H, Joo CK. 2004. Efficacy of the soft-shell technique using Viscoat and Hyal-2000. J Cataract Refract Surg, 30:2366-70.

Kitazawa Y, Kawase K, Matsushita H, et al. 1991. Trabeculectomy with mitomycin. A comparative study with fluorouracil. Arch Ophthalmol, 109:1693-8.
Kurtz S, Leibovitch I. 2002. Combined perfluoropropane gas and viscoelastic material injection for anterior chamber reformation following trabeculectomy. Br J Ophthalmol, 86:1225-7.

Liebmann JM, Ritch R, DiSclafani M, et al. 1990. Early intraocular pressure rise after trabeculectomy. Arch Ophthalmol, 108:1549-52.

Liesegang TJ. 1990. Viscoelastic substances in ophthalmology. Surv Ophthalmol, 34:268-93.

Lopes JF, Moster MR, Wilson RP, et al. 2006. Subconjunctival sodium hyaluronate $2.3 \%$ in trabeculectomy. A prospective randomized clinical trial. Ophthalmology, 113:756-60.

Luke C, Dietlein TS, Jacobi PC, et al. 2003. A prospective randomised trial of viscocanalostomy with and without implantation of a reticular hyaluronic acid implant (SKGEL) in open angle glaucoma. $\mathrm{Br} J \mathrm{Oph}$ thalmol, 87:599-603.

Marques DMV, Marques FF, Osher RH. 2004. Three-step technique for staining the anterior lens capsule with indocyanine green or trypan blue. J Cataract Refract Surg, 30:13-6.

McLeod D, James CR. 1988. Viscodelamination at the vitreoretinal juncture in severe diabetic eye disease. Br J Ophthalmol, 72:413-9.

Melles GRJ, Lander F, Rietveld FJR, et al. 1999A. A new surgical technique for deep stromal, anterior lamellar keratoplasty. $\mathrm{Br} J$ Ophthalmol, $83: 327-33$.

Melles GRJ, Remeijer L, Geerards AJM, et al. 2000. A quick surgical technique for deep, anterior lamellar keratoplasty using visco-dissection. Cornea, 19:427-32.

Melles GRJ, Waard PWT, Pameyer JH, et al. 1999B. Trypan blue capsule staining to visualize the capsulorhexis in cataract surgery. $J$ Cataract Refract Surg, 25:7-9.

Miyata K, Nagamoto T, Maruoka S, et al. 2002. Efficacy and safety of the soft-shell technique in cases with a hard lens nucleus. $J$ Cataract Refract Surg, 28:1546-50.

Moser CL, Martin-Baranera M, Garat M, et al. 2004. Corneal edema and intraocular pressure after cataract surgery. Randomized comparison of Healon5 and Amvisc Plus. J Cataract Refract Surg, 30:2359-65.

Osher RH, Cionni RJ, Cohen JS. 1996. Re-forming the flat anterior chamber with Healon. $J$ cataract Refract Surg, 22:411-5.

Oshika T, Eguchi S, Oki K, et al. 2004. Clinical comparison of Healon5 and Healon in phacoemulsification and intraocular lens implantation. Randomized multicenter study. J Cataract Refract Surg, 30:357-62.

Oshika T, Okamoto F, Kaji Y, et al. 2006. Retention and removal of a new viscous dispersive ophthalmic viscosurgical device during cataract surgery in animal eyes. Br J Ophthalmol, 90:485-7.

Pandey SK, Werner L, Apple DJ, et al. 2003. Viscoanesthesia. Part III: removal time of OVD/viscoanesthetic solutions from the capsular bag of postmortem human eyes. J Cataract Refract Surg, 29:563-7.

Perone JM, Popovici A, Ouled-Moussa R, et al. 2007. Safety and efficacy of two ocular anesthetic methods for phacoemulsification: topical anesthesia and viscoanesthesia (VisThesia). Eur J Ophthalmol, 17:171-7.

Petroll WM, Jafari M, Lane SS, et al. 2005. Quantitaitve assessment of ophthalmic viscosurgical device retention time using in vivo confocal microscopy. J Cataract Refract Surg, 31:2363-8.

Poyales-Galan F, Pirazzoli G. 2005. Clinical evaluation of endothelial cell decrease with VisThesia in phacoemulsification surgery. $J$ Cataract Refract Surg, 31:2157-61.

Poyer JF, Chan KY, Arshinoff SA. 1998. Quantitative method to determine the cohesion of viscoelastic agents by dynamic aspiration. J Cataract Refract Surg, 24:1130-5.

Pruett RC, Schepens CL, Swann DA. 1979. Hyaluronic acid vitreous substrate. A six-year clinical evaluation. Arch Ophthalmol, 97:2325-30.

Rado G, Berta A. 2002. Healon5 tamponade of corneal perforation during transplantation surgery. J cataract Refract Surg, 28:1520-1.

Rainer G, Menapace R, Findl O, et al. 2000. Intraocular pressure after small incision cataract surgery with Healon5 and Viscoat. J cataract Refract Surg, 26:271-6.

Rainer G, Menapace R, Schmid KE, et al. 2005. Natural course of intraocular pressure after cataract surgery with sodium chondroitin sulfate 4\%sodium hyaluronate 3\% (Viscoat). Ophthalmology, 112:1714-1718. 
Raitta C, Lehto I, Puska P, et al. 1994. A randomized, prospective study on the use of sodium hyaluronate (Healon) in trabeculectomy. Ophthalmic Surg, 25:536-9.

Saito M, Iida T. 2006. A surgical technique to protect the macular hole in indocyanine green-assisted vitrectomy. Ophthalmic Surg Lasers Imaging, 37:511-5.

Salvo EC Jr, Luntz MH, Medow NB. 1999. Use of viscoelastics posttrabeculectomy: a survey of members of the American Glaucoma Society. Ophthalmic Surg Lasers, 30:271-5.

Shimmura S, Shimazaki J, Omoto M, et al. 2005. Deep lamellar keratoplasty (DLKP) in keratoconus patients using viscoadaptive viscoelastics. Cornea, 24:178-81.

Shimmura S, Tsubota K, Oguchi Y, et al. 1992. Oxiradical-dependent photoemission induced by a phacoemulsification probe. Invest Ophthalmol Vis Sci, 33:2904-7.

Shin DB, Lee SB, Kim CS. 2003. Effects of viscoelastic material on the corneal endothelial cells in trabeculectomy with adjunctive mitomycinC. Korean J Ophthalmol, 17:83-90.

Sihota R, Saxena R, Agarwal HC. 2003. Intravitreal sodium hyaluronate and secondary glaucoma after complicated phacoemulsification. J Cataract Refract Surg, 29:1226-7.

Smith KD, Burt WL. 1992. Fluorescent viscoelastic enhancement. J Cataract Refract Surg, 18:572-6.

Sourdille P, Santiago PY, Villain F, et al. 1999. Reticualted hyaluronic acid implant in nonperforating trabecular surgery. $J$ cataract Refract Surg, 25:332-9.

Stegmann R, Pienaar A, Miller D. 1999. Viscocanalostomy for openangle glaucoma in black African patients. J Cataract Refract Surg, 25:316-22.

Takahashi H, Sakamoto A, Takahashi R, et al. 2002. Free radicals in phacoemulsification and aspiration procedures. Arch Ophthalmol, 120:1348-52.
Takahashi H, Suzuki H, Shiwa T, et al. 2006. Alteration of free radical development by ophthalmic viscosurgical devices in phacoemulsification. J Cataract Refract Surg, 32:1545-8.

Tamcelik N, Ozkiris A. 2004. A comparison of viscogoniotomy with classical goniotomy in Turkish patients. Jpn J Ophthalmol, 48:404-7.

Tamm ER, Carassa RG, Albert DM, et al. 2004. Viscocanalostomy in rhesus monkeys. Arch Ophthalmol, 122:1826-38.

Teekhasaenee C, Ritch R. 1986. The use of PhEA 34c in trabeculectomy. Ophthalmology, 93:487-91.

Tetz MR, Holzer MP. 2000. Two-compartment technique to remove ophthalmic viscosurgical devices. J Cataract Refract Surg, 26:641-3.

Torngren L, Lundgren B, Madsen K. 2000. Intraocular pressure development in the rabbit eye after aqueous exchange with ophthalmic viscosurgical devices. J Cataract Refract Surg, 26:1247-52.

Tseng SH, Chen FK. 1998. A randomized clinical trial of combined topical-intracameral anesthesia in cataract surgery. Ophthalmology, 105:2007-11.

Wild GJ, Kent AR, Peng Q. 2001. Dilation of Schlemm's canal in viscocanalostomy: comparison of 2 viscoelastic substances. J cataract Refract Surg, 27:1294-7.

Wilson RP, Lloyd J. 1986. The place of sodium hyaluronate in glaucoma surgery. Ophthalmic Surg, 17:30-3.

Yamashita T, Uemura A, Kita H, et al. 2006. Analysis of the retinal nerve fiber layer after indocyanine green-assisted vitrectomy for idiopathic macular holes. Ophthalmology, 113:280-4.

Zetterström C, Wejde G, Taube M. 2002. Healon $® 5$ :comparison of 2 removal techniques. J Cataract Refract Surg, 28:1561-4. 